\title{
FURTHER EXPERIENCES WITH KHELLIN IN ANGINA OF EFFORT
}

\author{
BY \\ H. A. DEWAR AND T. A. GRIMSON \\ From the Royal Victoria Infirmary, Newcastle-oni-Tyne
}

Received March 3, 1951

In our previous paper (1950) the efficacy of khellin and of glyceryl trinitrate in preventing angina of effort and the electrocardiographic changes that may accompany-it were compared in 12 susceptible patients. It was found that a single oral dose of $150 \mathrm{mg}$. khellin did have such an effect in a promising proportion of the patients but was less potent than a single $0.8 \mathrm{mg}$. (gr. 1/80) dose of glyceryl trinitrate. No ill-effects were produced by the khellin but no attempt was then made to give repeated treatment. Since then a number of papers have appeared on the subject of khellin. Best and Coe (1950) treated a group of nine patients with a daily oral dose of $150 \mathrm{mg}$. for from two to four weeks and found that the great majority had fewer attacks while under treatment and that it nearly always prevented pain when the patient was given an exercise, hypoxæmia, or ergonovine test. Nausea and vomiting occurred in only three of their patients but did not interfere with the use of the drug. Rosenman et al. (1950) treated a larger group of 30 patients with daily doses of 100-200 mg., Armbrust and Levine (1950) two groups of 28 and 25 patients with daily doses of $120 \mathrm{mg}$. or less, and Scott et al. (1951) a group of 20 patients with 17-240 mg. daily. Osher and Katz (1950) in a preliminary paper gave an account of their results with 19 patients, and Greiner and Gold (1950) in a brief summary their's with 39 patients. All these workers compared the frequency and severity of the anginal attacks while the patients were taking khellin with the results obtained with an inert control. Only Greiner and Gold failed to find any significant difference between the khellin and the control. Most of these papers, however, do also draw attention to the frequent toxic effects of the drug and acknowledge them as a serious drawback to its use. Fuller details of these and earlier papers are given in Table I, where so far as possible with data available, the results are compared with the series now reported, as well as with the original larger series described by Anrep et al. in 1949. The present investigation was undertaken in an attempt to reproduce Anrep's excellent results.

\section{METHOD OF INVESTIGATION}

Preparation and Dosage of Drug. The preparation used was that recommended to us by Professor Anrep and used by him and by Ayad (1948) namely ammicardine, an extract made from the plant ammi visnaga by Alpha Laboratories of Cairo and marketed in tablets each of which is said to contain $50 \mathrm{mg}$. of khellin. The same preparation, ammicardine, was used in our previous tests (1950) but then in the form of a liquid extract. Dummy tablets were also used. Made of sucrose, they did not have the same appearance as the khellin, but the high incidence of sideeffects that occurred with the khellin would in any case have prevented the patients from regarding the "genuine" and the dummy tablets as identical.

To begin with, a few patients were treated with the dose of khellin that Anrep et al. used, namely $100 \mathrm{mg}$. three times daily, but this proved so toxic that all subsequent cases were given an 
initial dosage of $50 \mathrm{mg}$. three times daily after meals, and this was reduced, if toxic symptoms appeared, to the most that the patient could take. Sometimes this was as little as $50 \mathrm{mg}$. every other day. No facilities were available for estimation of khellin in the blood stream, but since it is known that the drug accumulates in the body such small doses are not necessarily inert.

Selection of Patients. Thirty-four patients with typical angina of effort were selected for this trial. Both sexes were accepted, accident determining that there were 9 women and 25 men. All cases seen were graded into mild, moderate, or severe. Mild cases were so called when they were able to lead an almost normal life, only developing angina on acts of exertion, unusually vigorous for them. They were called severe either when pain limited their walking distance on the level to 50 yards or less, or when pain appeared at rest. A few observations showed that mild cases were unsatisfactory for assessment since their pain was too infrequent and irregular. Accordingly this series of 34 includes only moderate and severe ones. Most of these suffered from pain at least once each day, and all had it several times a week. The only other patients rejected were those who proved unreliable witnesses, usually through confusing a co-existing benign left breast pain with their true angina of effort. All the patients were interviewed and examined by both of us. Standard and præcordial leads V I-6, and in special cases unipolar limb leads, were always taken before the investigation, and repeated after it, if there was reason to suspect a change. All appeared to be suffering from coronary atherosclerosis except Case 13 who had aortic stenosis. All except one severe case were tested as out-patients although a few of the more severe had to be brought to hospital by ambulance or car, and one could barely take a few steps from her chair.

Method. At the first interview the patient was asked to co-operate in a test to find out whether some new drug would prove helpful in his (or her) case. He was given a postcard on which to record at the end of each day for a week how many times he had had anginal pain, and whether his most usual precipitating factor (a set walk or climb, particular working conditions, the mid-day meal or, as in one patient, the act of defæcation) had in fact precipitated it. He was then given tablets and instructed to take one three times daily after food for a week and to keep a similar record during this period. He was told that should any unpleasant side-effects develop he was to cease taking the tablets for 24 hours and then to resume at two a day; if still upset he was to cease for a further 24 hours and then resume at one daily; if still upset he was to abandon treatment. When seen after this first test week his card was scrutinized and he was asked for his opinion as to how the tablets had influenced his pain, and any ill-effects were enquired about. If khellin had been given first, a week was allowed to elapse without treatment and then a second and similar trial begun with the dummies. If the dummies had been used first, the patient went straight on to khellin. Care was taken that the groups who began with khellin and those who began with dummies were of equal numbers and were strictly comparable as to age and sex. At the end of the second test period the same enquiries were made as after the first. In several instances it became necessary to carry on one or other trial period for more than one week, either because the original dose of khellin had caused severe side-effects and a dose which would be well tolerated, had to be found, or else because some change in the environment, e.g. a change in the weather interfering with a patient's habitual walk, a holiday from work, an intercurrent infection, or a period of shore leave in a seafaring man, had prevented the two trial periods remaining comparable.

At the end of the second trial period the value of the drug was assessed, partly by comparing the number of recorded attacks in the control, khellin, and dummy periods, partly on the basis of the patients' own opinion and our appraisal of the reliability of that opinion. Despite careful instructions patients were not very reliable in keeping records of their anginal attacks. Some attacks would be regarded as " too slight to be worth recording," others would be half forgotten so that only " several " would be put down. In other patients status anginosus would appear and to record it simply as one attack would be misleading. But by combining these records with the patients' expressed opinion, and by enquiring after and allowing for any variation in his environment and habits, it was not difficult for us to come to a confident conclusion as to the extent to which each patient's angina had really been alleviated. 
RESULTS below.

The four categories into which the 34 patients were placed and the number in each were as given

No Improvement Slight Improvement 13 11

$\begin{array}{ccc}\text { Moderate Improvement } & \text { No pain } & \text { Total } \\ 9 & 1 & 34\end{array}$

Where a patient recorded improvement with the dummy tablets, the degree of this-only once was it more than slight, and then the khellin had no beneficial effect-was subtracted from the result claimed for khellin. Full details of these results are given in Table II. Shortly, about one-third of the patients tested obtained worth while relief. It is perhaps of interest that the results were significantly better in the hypertensive (B.P. more than 160/90) than in the others.

TABLE I

Summary of Clinical Trials with Khellin

\begin{tabular}{|c|c|c|c|c|c|c|c|c|}
\hline \multirow{2}{*}{ Authors } & \multirow{2}{*}{$\begin{array}{l}\text { No. } \\
\text { of } \\
\text { cases }\end{array}$} & \multirow{2}{*}{$\begin{array}{l}\text { Daily } \\
\text { dose } \\
\text { in } \mathrm{mg} .\end{array}$} & \multicolumn{3}{|c|}{ Response to Treatment } & \multicolumn{3}{|c|}{ Toxic Effects } \\
\hline & & & Satisfactory & Doubtful & Failure & Mild or Moderate & Severe & Total \\
\hline Ayad (1948) $\quad .$. & 23 & $100-200$ & $83 \%$ & & $17 \%$ & 0 & 0 & 0 \\
\hline$\underset{(1949)}{\operatorname{Anrep} e t}$ al. $\quad \cdots$ & 250 & c. $\begin{array}{r}120-150 \\
50-100\end{array}$ & \multicolumn{2}{|c|}{$90 \%$} & $10 \%$ & A few & None & A few \\
\hline $\begin{array}{l}\text { Rosenman et al. } \\
\text { (1950) }\end{array}$ & 30 & $100-200$ & $40 \%$ & $53 \%$ & $7 \%$ & $20 \%$ & $33 \%$ & $53 \%$ \\
\hline \multirow{2}{*}{$\begin{array}{l}\text { Armbrust Gp. I } \\
\text { and } \\
\text { Levine Gp. II }\end{array}$} & \multirow{2}{*}{$\begin{array}{l}28 \\
25\end{array}$} & \multirow{2}{*}{$\begin{array}{l}120 \\
\text { Later } \\
40-80\end{array}$} & $28.5 \%$ & $28 \cdot 5 \%$ & \multirow{2}{*}{$\begin{array}{l}43 \% \\
48 \%\end{array}$} & $43 \%$ & $25 \%$ & \multirow{2}{*}{$\begin{array}{l}68 \% \\
56 \%\end{array}$} \\
\hline & & & \multicolumn{2}{|c|}{$52 \%$} & & \multicolumn{2}{|l|}{$56 \%$} & \\
\hline $\begin{array}{l}\text { Best and Coe } . . \\
(1950)\end{array}$ & 9 & 150 & $78 \%$ & $11 \%$ & $11 \%$ & $33 \%$ & 0 & $33 \%$ \\
\hline $\begin{array}{l}\text { Greiner and } \\
\text { Gold (1950) .. }\end{array}$ & 39 & $100-150$ & & & $100 \%$ & & & $?$ \\
\hline $\begin{array}{l}\text { Osher and Katz } \\
\text { (1950) }\end{array}$ & 19 & $120+$ & $\begin{array}{l}84 \% \\
79 \%\end{array}$ & $5 \%$ & $16 \%$ & Several & $10 \%$ & $?$ \\
\hline $\begin{array}{ll}\text { Scott } e t \text { al. } & \text { (1950) }\end{array}$ & 20 & $\begin{array}{l}17-240 \\
\text { Av } 106\end{array}$ & $20 \%$ & $35 \%$ & $45 \%$ & & & $85 \%$ \\
\hline Present Series .. & 34 & $\begin{array}{c}150 \\
\text { Later } \\
25-150\end{array}$ & $29 \%$ & $32 \%$ & $38 \%$ & $76 \%$ & $21 \%$ & $97 \%$ \\
\hline
\end{tabular}

Toxic Effects. The high incidence of these is shown in Tables I and II. On a dosage of $150 \mathrm{mg}$. daily, their incidence was:-

$\begin{array}{ccccc}\text { None } & \text { Slight } & \text { Moderate } & \text { Severe } & \text { Total } \\ 1 & 8 & 18 & 7 & 34\end{array}$

Gastric upset, comprising dyspepsia, nausea, or heartburn, occurred in 33 of the 34 patients and in 11 led to vomiting. Giddiness was complained of six times, lassitude and headache three times, and two patients developed a mild desquamating dermatitis. In many instances the gastric symptoms began soon after the first tablet had been swallowed, presumably owing to a local effect upon the stomach, but more often the onset was delayed until after several tablets had been taken. Since the drug accumulates in the body, it is probable that in these patients the blood concentration had risen to a toxic level. 
TABLE II

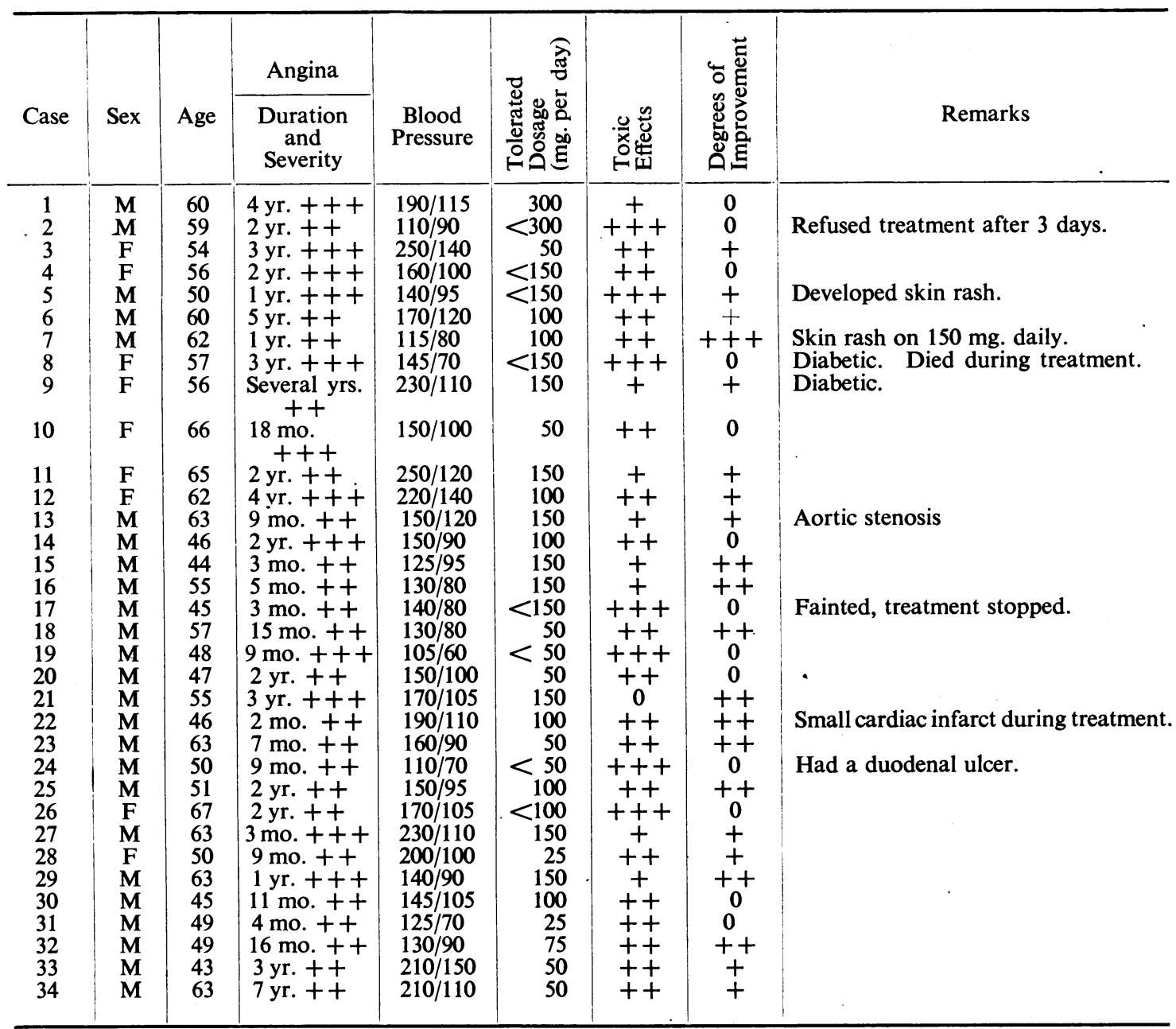

Severity of Angina: $++=$ moderate,$+++=$ severe.

Toxic Effects of Khellin: $+++=$ sufficient to cause treatment to be abandoned, $+=$ not sufficient to cause reduction of dose below $150 \mathrm{mg}$. daily.

Degree of Improvement: $+=$ slight,$++=$ moderate,$+++=$ no pain.

\section{SUMMARY}

Thirty-four patients with moderate or severe angina of effort were treated with khellin, beginning with doses of $150 \mathrm{mg}$. daily, and the effect of the drug assessed against dummy controls.

Ten patients $(29 \%)$ were moderately or greatly improved and $13(38 \%)$ were total failures.

There was a high incidence of toxic effects on this dosage, and seven patients had to abandon treatment.

The drug has a limited place in the treatment of angina of effort.

Our results with this drug agree well with those of Armbrust and Levine and also with those of Scott et al. (Table I). Our incidence of toxic effects is higher, presumably because the $150 \mathrm{mg}$. daily dose was persevered with for longer. Possibly with more careful attention to dosage a few 
patients who were failures might have obtained useful relief, but it is very doubtful whether the proportion of worthwhile results with this substance in moderate or severe angina can be raised above 40 per cent. We agree with these workers that the toxic effects of khellin constitute an important drawback to its use.

We wish to express our thanks to colleagues who have referred cases to us, and especially to Dr. W. G. A. Swan of the Newcastle General Hospital. We are also grateful to the Governors of the Royal Victoria Infirmary for a grant towards expenses.

\section{REFERENCES}

Ayad, H. (1948). Lancet, 1, 305.

Anrep, G. V., Kenawy, M. R., and Barsoum, G. S. (1949). Amer. Heart J., 37, 531.

Armbrust, and Levine, S. A. (1950). Amer. J. med. Sci., 220, 127.

Best M. M., and Coe, W. S. (1950). Circulation, 2, 344.

Dewar, H. A., and Grimson, T. A. (1950). Brit. Heart J., 12, 54.

Greiner, T., and Gold, H. (1950). J. Pharmacol. and Exper. Therap., 98, 10.

Osher, H. L., and Katz, K. H. (1950). Boston M. Quart., 1, 11.

Rosenman, R. H., Fishman, A. P., Kaplan, S. R., Levin, H. G., and Katz, L. N. (1950). J. Amer. med. Assoc., $143,160$.

Scott, R. C., Iglauer, A., Green, R. S., Kaufman, J. W., Berman, B., and McGuire, J. (1951). Circulation, 3, 80. 